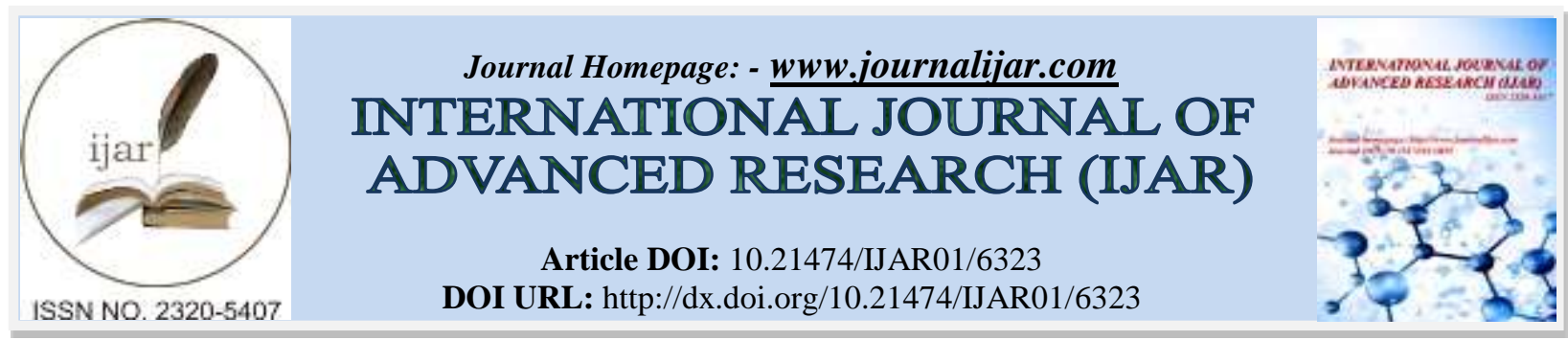

RESEARCH ARTICLE

\title{
SUPPRESSION OF MAMMARY CARCINOMAS BY ALPHA-LINOLENIC ACID: PART I. EFFECT OF EXTRACTION METHODS ON QUALITY AND GC-MS ANALYSIS OF OIL FROM FLAXSEED (LINUM USITATISSIMUM L.).
}

Vanita S. Bhat ${ }^{1}$ and Dr. Basavaraj Madhusudhan ${ }^{2}$.

1. Department of Food Technology, Davangere University, Shivagangothri, Davangere- 577 007, Karnataka.

2. Department of Studies and Research in Food Technology Shivagangothri, Davangere- 577 007, Karnataka.

\section{Manuscript Info}

\section{Manuscript History}

Received: 16 November 2017

Final Accepted: 18 December 2017

Published: January 2018

\section{Key words:-}

flaxseed oil, cold press, ultrasonic extraction, Soxhlet extraction, oil quality, GC-MS analysis .

\begin{abstract}
:
health and disease is gaining remarkable attention in food products, formulations and supplements. Flaxseed oil is also one among the best sources of ALA. In this paper, effectiveness of ultrasonic extraction of oil from finely ground flaxseed flour is compared to the other two conventional extraction methods. The yields of oils in cold pressed method (30.14\%), ultrasonic extraction (48.05\%) and Soxhlet extracted $(43.01 \%)$ were measured. The yield of oil from finely ground flaxseed flour by ultrasonic extraction was higher than that of the cold pressed and Soxhlet extraction methods. From GC-MS analysis, significant degradation of constituents of oils was found ( $p>0.05)$. Unsaturated fatty acids were more in oil extracted using ultrasonic method in comparison to cold pressed and Soxhlet extraction methods. In oils, ALA was significantly higher ranging between $47.99 \%$ - 55.83\% than oleic acid (19.32 25.14\%), linoleic acid (11.42 - 13.68\%), and stearic acid (04.46 - 06.34\%) was significantly higher than other saturated fatty acids. Among the extraction methods, ultrasonic extraction method was considered promising and industrially scalable in terms of reduced extraction time, solvent consumption, yield, stability and quality in comparison with other conventional extraction methods.
\end{abstract}

Therapeutic role of alphaCopy Right, IJAR, 2018,. All rights reserved. linolenic acid (ALA) in human

\section{Introduction:}

Flaxseed (Linum Usitatissimum L.) is gaining unusual importance in modern medicine and as a dietary supplement due to abundant source of oil (36-45\%) containing higher concentrations of alpha-linolenic acid (ALA, 18:3, an omega-3 / n-3fatty acid) in the range of $26-60 \%$. The other prime source of functional therapeutic constituents of flaxseeds includes lignans and fiber. These potential ingredients have remarkable health benefits including cancer prevention. ALA is an essential polyunsaturated fatty acid (PUFA) needs to be supplied from plant-based dietary sources such as seeds, nuts and green-leafy vegetables (Swanson, D.et al.,(2012),Welch, A. et al.,(2010)). While in the human body, ALA undergoes sequential desaturation and elongation steps by enzymatic reactions. Through which body synthesizes two prominent long chain fatty acids eicosapentaenoic acid (EPA, 20:5, n-3) and docosahexaenoic acid (DHA, 22:6, n-3) for vital bodily activities like regulating membrane fluidity, protein and cellular functions, eicosanoid metabolism, gene expression and cell signaling (Kinney, A. et al., (2004), Calder, P. et al.,(2012)). Recent reports are highly promising with chemotherapeutic and desirable characteristics of n-3fatty 
acids, which plays remarkable role in shrinking tumor cells in prostate and breast cancer (Alexander, W.(2013),MacLennan, M. et al., (2010)). Cell line studies have shown that ALA alone and whole flaxseed consisting of 57\% ALA strongly suppressed the over expression of HER2+ in mammary carcinomas and significant reduction in tumour growth, MCF-7 cells in overiectomized mice in comparison with a diet containing no flaxseed (Goyal, A. et al.,(2014), Ayala, A. et al.,(2014), Menendez, J. et al.,(2006), Chen, J. et al.,(2007)). In contrast, n-3 PUFA have been shown to reduce the risk of mammary carcinogenesis (Caygill, C. et al., (1996)). In conjunction with these effects, it was found that flaxseed consumption actually enhanced the inhibitory effects of Tamoxifen, a drug used in breast cancer treatment. A study on mice treated with MDA-MB-231 BC cells comparing diets of corn oil (1\% ALA) with diets of canola oil (10\% ALA) found the tumor growth rate to be significantly reduced in canolafed mice (Hardman, W. (2007)). Evidence of DHA being the primary effector in inhibiting tumorogenesis was observed in patients with localized breast cancer where the adipose tissue with high concentrations of DHA showed the greatest extent of tumor regression (Bougnoux, P. et al., (1999)). DHA itself has also been linked to down regulation of the HER-2 oncogene and to the reduction of cancer cell viability and DHA has been shown to synergistically enhance the cytotoxic activity in some cases by up to 13-fold (Menendez, J. et al., (2005)).

Unfortunately, the oil from finely ground flaxseed flour has low oxidative stability that necessitates the focus on the health benefits, yield and quality. In order to improve the yield and optimize the extraction, novel methods are being tried out from time and again. The present work has focused mainly on the extraction of quality oil and to assess the dietary individual fatty acids profile using GC-MS analysis that are highly warranted. The investigations will provide a basis for new approaches to improve our understanding on the role of essential fattyacids in breast cancer prevention and treatment. The study will allow us to attend the existing inconsistency with regard to the effects of specific classes of fatty acids, especially ALA-enriched, EPA-enriched and DHA-enriched diets and their role in controlling breast cancer using Nanocapsules / nanosome-formulations of oil / candidate fatty acid(s) to the targeted site. We use our nanotechnology expertise to exploit the most promising ability of n-3 PUFA in shrinking breast cancer tissue development in the early stages, in a cost-effective manner.

\section{Materials and Methods:}

All solvents and standards used in the experiments were purchased from Sigma. All the reagents used were of analytical grade. Cold pressed flaxseed oil was procured from Vishal Organix, Mumbai.

\section{Flaxseed Materials:}

Brown variety of flaxseeds being used for consumption was purchased from the local market of Davangere, Karnataka, India. University of Agricultural Sciences, Hebbal, Bangalore,India identified these cultivars as RBVF-01. Upon arrival, the flaxseedswere cleaned, moisture content was determined, finely ground using coffee blender $(4600 \mathrm{rpm})$ and sieved through a mesh $(0.25 \mathrm{~mm})$, packaged in plastic bags, sealed, stored at $-18{ }^{0} \mathrm{C}$ and immediately proceeded further to obtain defatted meal and oil by different extraction methods.

\section{Extraction of oil by Ultrasonication:}

In ultrasonic extraction, Sonics VCX750 (Vibra-CellTM Ultrasonic Processors, Newton, USA) was used for ultrasound treatment at different time and amplitude levels to release oil constituents. The predetermined extraction parameters are used as follows: extraction time, $40 \mathrm{~min}$; extraction temperature, $35^{\circ} \mathrm{C}$; and solvent/sample ratio, $15: 1$, at a fixed ultrasonic frequency of $40 \mathrm{kHz}$ and power of $150 \mathrm{~W}$. Under these conditions, the crude oil obtained was $48 \%$ and upon re-extraction with absolute ethanol, the pure oil was recovered $(87.18 \pm 0.12 \%)$ for finely ground flaxseed flour, which well matches with the expected value $(\sim 4 \%)$. The ultrasound probe (19 mm diameter) was attached to the ultrasound transducer to generate constant frequencyof $40 \mathrm{kHz}$ and maximum amplitude of $58 \mu \mathrm{m}$ for treatment of the sample after preliminary attempts to stabilize the desired condition. Ten grams of finely ground flaxseed flour were weighed and placed in a glass flask. Then $150 \mathrm{~mL}$ of ethanolwas added to the flask. The solution was transferred to a $200 \mathrm{~mL}$ polypropylene container. For each ultrasonic treatment, the Sonics VCX750 was set to $35^{\circ} \mathrm{C}$ and theultrasonic treatment was initiated for $40 \mathrm{~min}$ of extraction time and repeated thrice for agreeing values.

\section{Extraction of oil by Soxhlet Method:}

Soxhlet extraction was carried out (Basavaraj, M. et al., (2000)) with slight modification. Finely ground flaxseed flour was $(2.5 \mathrm{gm})$ packeted in Whatman No.1 filter paper and extracted using hexane as a solvent for 16 hours at $70{ }^{\circ} \mathrm{C}$. Then the solvent was recovered using under vacuum pressure at $40{ }^{\circ} \mathrm{C}$ using and the defatted meal fraction and residual oil were weighed and stored at $4^{0} \mathrm{C}$.

\section{Extraction of oil by Cold Press:}


The oil of finely ground flaxseed flour by Cold Press method was acquired from Vishal Organnix (Mumbai, Maharashtra, India), dried over anhydrous $\mathrm{Na}_{2} \mathrm{SO}_{4}$ and stored in a dark glass bottle and kept at $4^{\circ} \mathrm{C}$ until analysis.

\section{Physico-Chemical parameters:}

Physiochemical parameters such as moisture content, free fatty acid value (FFAV), iodine value (IV), saponification value (SV) and peroxide value (PV) were analysed for all the three oil samples (AOAC Official Methods., (1995), Dave, B. et al.,(2009)).

In-vitro antioxidant activity:

The antioxidant potential was used for the determination of anion scavenging activity of finely ground flaxseed flour oils using DPPH (1,1-diphenyl-2-picrylhydrazyl) as reported by (Chen, H. et al.,(2016))with slight modification. The absorbance was measured at $520 \mathrm{~nm}$. The free radical scavenging potential of finely ground flaxseed flour oils to scavenge the DPPH radical was calculated with the following equation:

$$
\text { Inhibition }(\%)=\left[\left(\mathrm{A}_{0}-\mathrm{A}_{\mathrm{I}}\right) / \mathrm{A}_{0}\right] \mathrm{X} 100
$$

Here, $A_{0}$ is the absorbance of the blank; $A_{I}$ is the absorbance of the sample.

The DPPH free radical scavenging potential of finely ground flaxseed flour oils were compared with appropriate positive controls, BHT and alpha-tocopherol.

\section{GCMS analysis of oils:}

An aliquot of oil samples were diluted in dichloromethane (1:200) for GC analysis, separately. A $2 \mu \mathrm{L}$ volume of each sample was injected in to Agilent 7890A series, GC-MS System (Agilent, USA) was used for the analysis attached with CTC-PAL autosampler (CTC Analytics AG, Switzerland). The nonpolar fused silica HP5MSTM (5\% phenyl polymethylsiloxane) capillary Column $(30 \mathrm{~m} \times 0.25 \mathrm{~mm}$ i.d. and $0.25 \mu \mathrm{m}$ film thickness $)$ and mass detector was used. GC-MS spectra for finely ground flaxseed flour oils were obtained using the following conditions: the carrier gas used $\mathrm{He}$ was with electron ionisation energy $70 \mathrm{eV}$, ion-source temperature $200^{\circ} \mathrm{C}$ and the interface temperature $280^{\circ} \mathrm{C}$; the splitless mode at $250{ }^{\circ} \mathrm{C}$ inlet temperature, $0.1 \mathrm{ml}$ injection volume with helium gas at $1 \mathrm{ml} / \mathrm{min}$.; data acquisition was performed with MassLab software for the mass ranges $30-600 \mathrm{amu}$ with a scan speed of $1 \mathrm{scan} / \mathrm{s}$ were used. The oven temperature was programmed as $70^{\circ} \mathrm{C}$ ( $3 \mathrm{~min}$ hold) rose at $4{ }^{\circ} \mathrm{C} / \mathrm{min}$ to $202{ }^{\circ} \mathrm{C}$ (20 min hold) for analysis (Rishika, C.et al.,(2015)).

\section{Statistical analysis:}

All analyses were carried out in triplicate. Statistical analysis was performed using the Proc ANOVA in SAS (software version 8). Results are presented as the means \pm SD from three triplicates of each sample. Statistical significance was evaluated at $\mathrm{p}<0.05$ level.

\section{Results and Discussion:}

\section{Effect of extraction methods:}

Three different extraction systems were compared to determine the oil extractability of the commercial cold pressed method and conventional Soxhlet extraction method with the most recent ultrasonic extraction method in terms of \% yields, quality, stability, antioxidant capacity and source of essential fatty acids. The yield in cold pressed, ultrasonic extraction and Soxhlet methods was $30.14 \%, 48.05 \%$ and $43.01 \%$, respectively. The stability of the fatty acid mainly depends upon the physicochemical properties determined according to standard AOAC methods, as listed in Table 1.

Table 1:- Physicochemical characteristics of finely ground flaxseed flour oils extracted by cold pressed extraction, ultrasonicextraction and Soxhlet extraction methods

\begin{tabular}{|l|c|c|c|}
\hline Parameters & Cold pressed extraction & Ultrasonic extraction & Soxhlet extraction \\
\hline Iodine value $\left(\mathrm{g} \mathrm{I}_{2} / 100 \mathrm{~g}\right.$ oil) & 176 & 161 & 147 \\
\hline $\begin{array}{l}\text { Saponification value }(\mathrm{mg} \\
\text { KOH/g oil) }\end{array}$ & 190 & 190 & 219 \\
\hline $\begin{array}{l}\text { Free Fatty Acid value (mg } \\
\text { KOH/g oil) }\end{array}$ & 0.80 & 1.26 & 1.41 \\
\hline Peroxide value (m.Eq of & 0.95 & 1.92 & 1.83 \\
\hline
\end{tabular}




\section{$\mathrm{O}_{2} / \mathrm{kg}$ oil)}

The decreased number of iodine value, increased number of saponification value, free fatty acid value and the peroxide value indicates the variation in the oil quality which is falling towards unacceptable level for the food, cosmetic and fodder use industries due to different oil extraction methods.

The in-vitro determination of antioxidant potential of finely ground flaxseed flour oils samples extracted through 3 different methods are shown in Fig. 1. The free radical scavenging potential of finely ground flaxseed flour oils to scavenge the DPPH radical was calculated in terms of percent inhibition. The DPPH activity is indicated as $\mathrm{IC}_{50}$ values ranging from day 0 to 90 days period. On day 0 it was indicated $30.14,36.81,30.53$ for cold pressed extraction, ultrasonicextraction, Soxhlet extraction as shown in Figure 1. The same was extended up to 90 days indicated as $32.70,39.90$, and 31.84 . The oils exhibited $44.62 \%$. DPPH free radical scavenging potential at $500 \mu \mathrm{g} /$ $\mathrm{mL}$, and the reference compounds BHT and $\alpha$-tocopherol exhibited 30 and $64.15 \%$ inhibition at $50 \mu \mathrm{g} / \mathrm{mL}$ levels, respectively (Fig. 1).

Fig. 1:- DPPH activity of flaxseed oil extracted by cold press, ultrasonic extraction and Soxhlet extraction methods

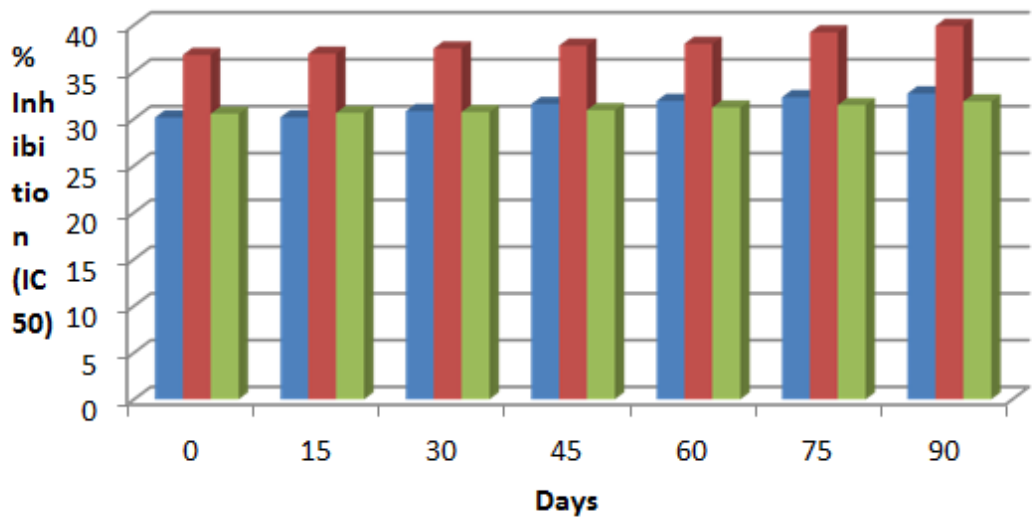

Cold Press Extraction

Ultrasonic Extraction

Soxhlet Extraction

\section{GC-MS analysis:}

The fatty acids profile of finely ground flaxseed flour oils extracted by cold pressed extraction, ultrasonic extraction and Soxhlet extraction methods is presented in Table 2 and the typical gas chromatogram in the GC-MS analysis of the oils is shown in Fig. 2a-d.

Table 2:- Fatty acids profile of flaxseed oils extracted by cold pressed extraction, ultrasonic extraction and Soxhlet extraction methods

\begin{tabular}{|c|c|c|c|c|}
\hline & Fatty acids & $\begin{array}{c}\text { Soxhlet extraction } \\
(\%)\end{array}$ & $\begin{array}{c}\text { Ultrasonicextraction } \\
(\%)\end{array}$ & $\begin{array}{l}\text { Cold pressed } \\
\text { extraction }(\%)\end{array}$ \\
\hline & & r Omega 3 fatty aci & & \\
\hline 1. & Stearic acid (C18:0) & 04.46 & 04.67 & 06.34 \\
\hline 2. & linolenic acid (C18:3) & 51.46 & 55.83 & 47.99 \\
\hline 3. & Cis $8,11,14$ Eicosanoic acid(C18:3) & 00.07 & 00.06 & 00.19 \\
\hline 4. & cis $11,14,17$ eicosanoic acid $(\mathrm{C} 18: 3)$ & 00.02 & 00.04 & 00.03 \\
\hline 5. & Eicosapentaenoic acid (C18:3) & 00.00 & 00.00 & 00.05 \\
\hline 6. & Docosahexaenoic acid (C18:3) & 00.00 & 00.00 & 00.00 \\
\hline & Total & 56.01 & 60.06 & 54.60 \\
\hline & & or Omega 6 fatty aci & & \\
\hline 1. & Linoleadic acid (C18:2) & 00.00 & 00.04 & 00.05 \\
\hline 2. & Linoleic acid (C18:2) & 11.42 & 13.68 & 11.78 \\
\hline
\end{tabular}




\begin{tabular}{|c|c|c|c|c|}
\hline 3. & Gamma linolenic acid (C18:2) & 00.29 & 00.19 & 00.39 \\
\hline 4. & $\begin{array}{l}\text { Methyl cis 5,8,11,14 Eicosatetranoic } \\
\text { acid (C18:2) }\end{array}$ & 00.07 & 00.00 & 00.05 \\
\hline 5. & cis 13,16 , Docosadienoic acid (C18:2) & 00.12 & 00.08 & 00.12 \\
\hline 6. & cis8,11,14, Eicosatrienioc acid (C18:2) & 00.06 & 00.07 & 00.04 \\
\hline & Total & 11.96 & 14.06 & 12.43 \\
\hline \multicolumn{5}{|c|}{ Major Omega 9 fatty acids } \\
\hline 1. & Elaidic acid (C18:1) & 00.11 & 00.02 & 00.04 \\
\hline 2. & oleic acid (C18:1) & 23.10 & 19.32 & 25.14 \\
\hline 3. & Arachidic acid (C18:1) & 00.25 & 00.17 & 00.25 \\
\hline 4. & cis 11,eicosanoic acid (C18:1) & 00.02 & 00.00 & 00.22 \\
\hline 5. & cis11,14eicosapentanoic acid (C18:1) & 00.00 & 00.00 & 00.00 \\
\hline 6. & Erucic acid (C18:1) & 00.12 & 00.00 & 00.06 \\
\hline 7. & Tricosanoic acid (C18:1) & 00.11 & 00.00 & 00.00 \\
\hline 8. & Nervonic acid (C18:1) & 00.03 & 00.00 & 00.05 \\
\hline 9. & 5,8,11,eicosatrienoic acid (C18:1) & 00.00 & 00.00 & 00.00 \\
\hline \multicolumn{2}{|r|}{ Total } & 23.74 & 19.51 & 25.76 \\
\hline
\end{tabular}

Fig. 2: GC-MS analysis of finely ground flaxseed flour oils extracted by cold pressed extraction, ultrasonic extraction and Soxhlet extraction methods; Fig. 2a: Fatty acids standard; Fig. 2b: Fatty acids of Cold Pressed oil;

Fig. 2c: Fatty acids of Ultrasonic Extracted oil; and Fig. 2d: Fatty acids of Soxhlet Extracted oil.

Fig. 2a: Fatty acid standards

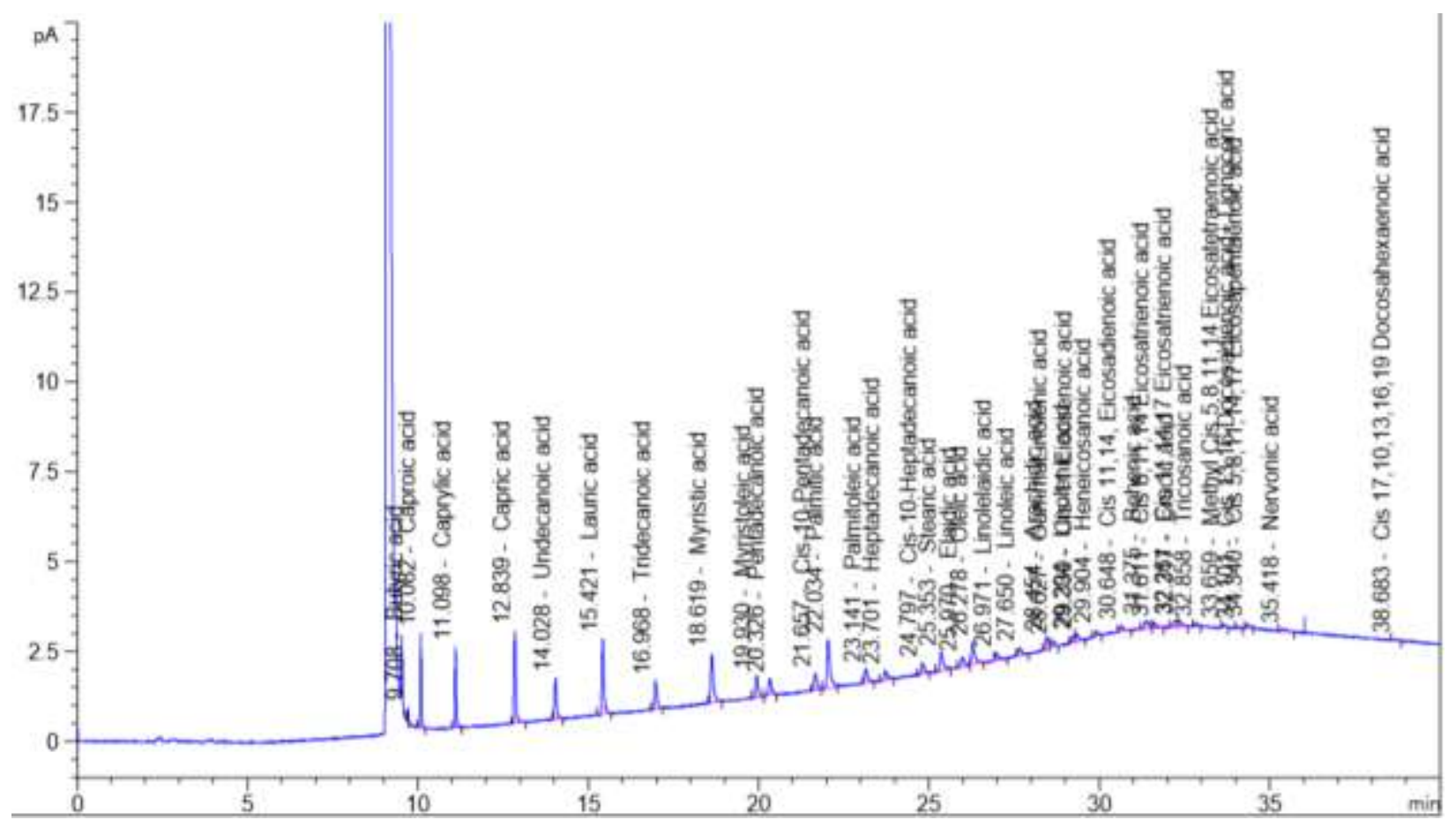

Fig. 2b: Fatty acids of Cold Pressed oil 

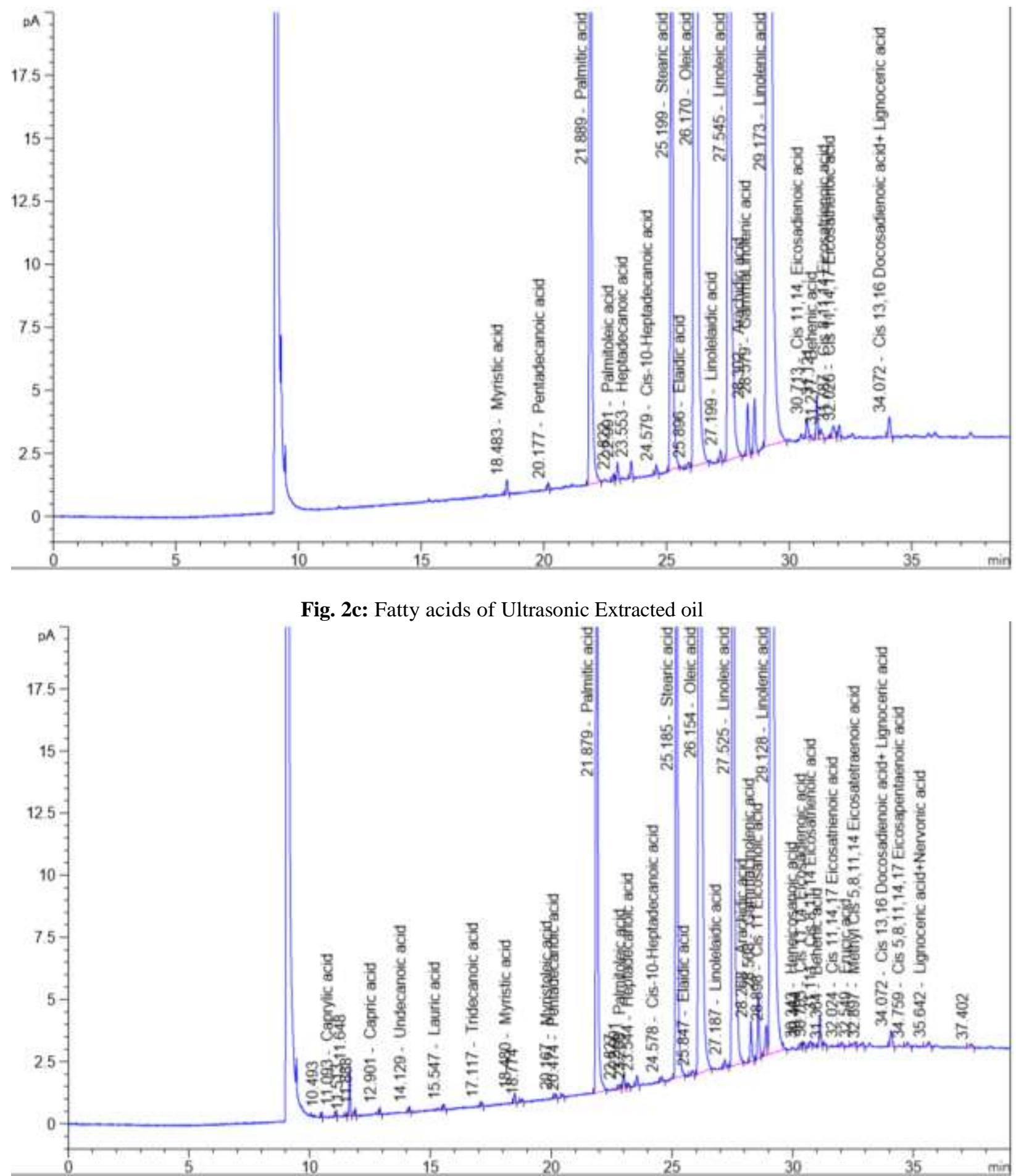

Fig. 2d: Fatty acids of Soxhlet Extracted oil 


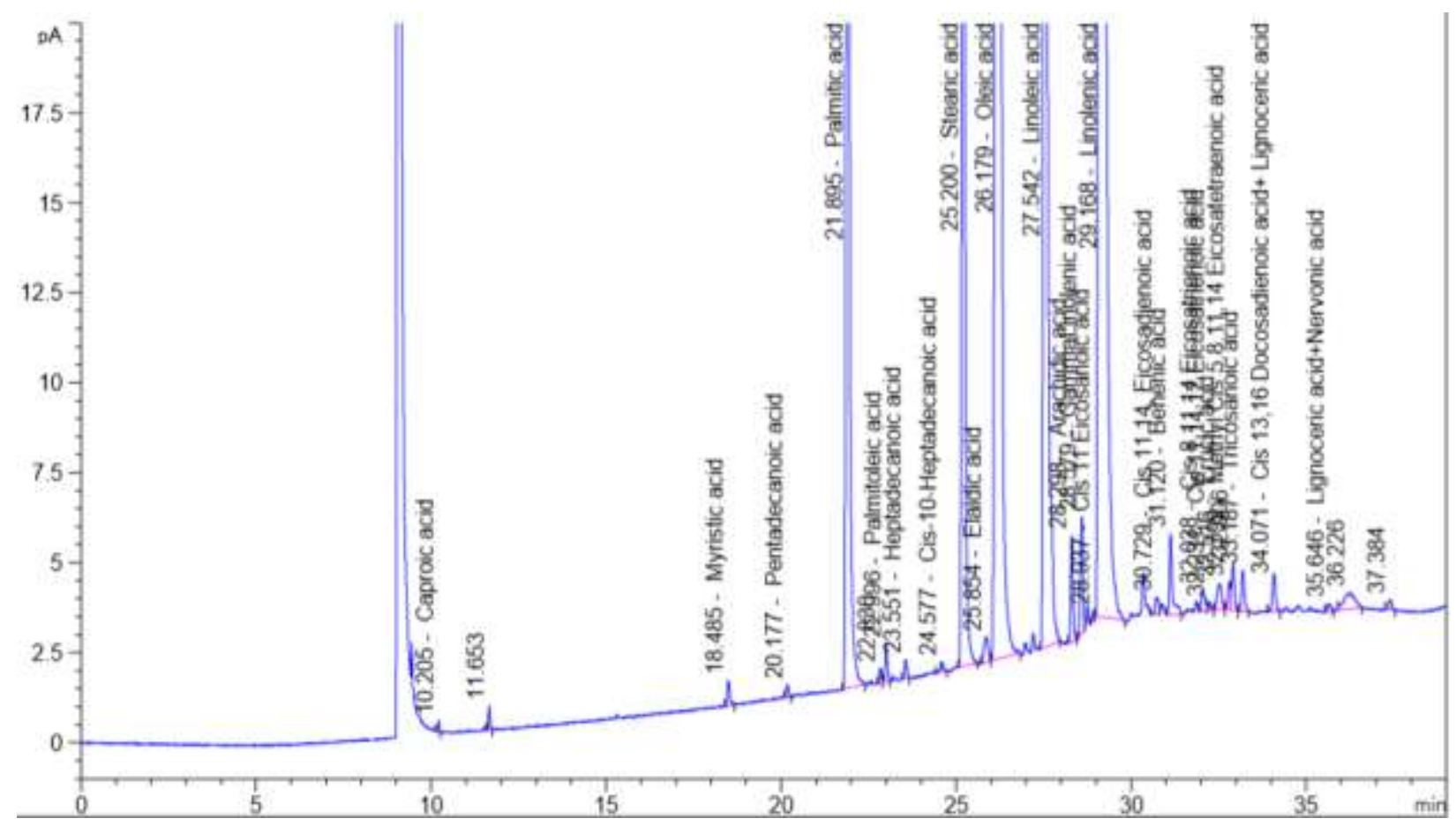

From analysis, it was observed that finely ground flaxseed flour oils were composed of some major omega-3 fatty acids, significant amount of linolenic acid along with stearic acid in cold pressed extraction $(47.99 \%$ and $06.34 \%$ ), ultrasonic extraction (55.83\% and $04.67 \%$ ) and Soxhlet extraction (51.46\% and 04.46\%) oils, respectively. The oils were found to contain linoleic acid, a leading omega- 6 fatty acid in appreciable amount in cold pressed extraction (11.78\%), ultrasonic extraction (13.68\%) and Soxhlet extraction (11.42\%). Of omega-9 fatty acids, oleic acid was the highest among other fatty acids in the oils obtained from cold pressed extraction (25.14\%), ultrasonic extraction (19.32\%) and Soxhlet extraction (23.10\%) methods. The oils contained linolenic acid as a predominant unsaturated fatty acid followed by oleic acid and linoleic acid as observed.

\section{Conclusions:-}

In this investigation, we revealed significant differences in $\%$ yield, quality, stability, antioxidant capacity and fatty acid composition of flaxseed oils obtained by three different extraction methods. We found that ultrasonic extraction method can perform more reliable qualitative and quantitative extraction of oils from the ground flaxseed flour samples in comparison with cold pressed and Soxhlet extraction methods. The results indicated that the ultrasonic waves in the set conditions did not adversely affect the fatty acids composition in finely ground flaxseed flour oils. The GC-MS was found to be the most suitable technique for the characterization of fatty acids profile of flaxseed oils. However, GC-MS system for the analysis of flaxseed oil samples predominantly composed of ALA. Presence of other two fatty acids oleic acid and linoleic acid along with minor components should not be ignored as they contribute to the overall qualities of the flaxseedoils in maintaining n3-to-n6 ratio. In conclusion, the ultrasonic extraction was found to be the best method to extract oil with better yield and quality from flax seed.

\section{Aknowledgements:-}

The authors wish to thank Vishal Organnix (Mumbai, Maharashtra, India) for Cold Press flaxseed oil sample and Mrs. Nagalakshmi N.S., Director, Vsix Analytical Labs Pvt Ltd., Bangalore, India for help with GC-MS analysis. The financial assistance received from DST-SERB, Govt. of India, New Delhi (sponsored project Grant No SB/EMEQ-429/2014) for providing Junior Research Fellowship is duly acknowledged. Thanks are also due to Davangere University, Karnataka, for facilities and encouragement. 


\section{References:-}

1. Alexander, W. (2013): Prostate cancer risk and omega-3 fatty acid intake from fish oil. Pharmacy andTherapeutics.,38:561-564.

2. AOAC (Association of Official Analytical Chemists).(1995): Official Methods of Analysis, 16th Edition. AOAC International, Gaithersburg, MD.

3. Ayala, A., Muñoz,MF., Argüelles, S. (2014): Lipid peroxidation: production, metabolism, and signaling mechanisms of malondialdehyde and 4-hydroxy-2-nonenal. Oxid Med Cell Longev.,2014: 360438

4. Basavaraj, M., Dennis, W., Jurgen, S., Kristi, T., James, G. (2000):A Dry Mechanical Method for Concentrating the Lignan Secoisolariciresinol Diglucoside in Flaxseed. Lebensmittel-Wissenschaft undTechnologie.,33: 268-275.

5. Bougnoux, P., Germain, E., Chajes, V., Hubert, B., Lhuillery, C., Le,FO., Body, G., Calais, G. (1999): Cytotoxic drug efficacy correlates with adipose tissue docosahexaenoic acid level in locally advanced breast carcinoma. Br J Cancer., 79:1765-1769.

6. Calder, P. C. (2012): The role of marine omega-3 (n-3) fatty acids in inflammatory processes, atherosclerosis and plaque stability. MolNutr Food Res., 56:1073-80.

7. Caygill, C. P., Charlett, A., Hill, M. J. (1996): Fat, fish, fish oil and cancer. Br J Cancer., 74:159-164.

8. Chen, H., Qiu, S., Gan, J., Li, Z., Nirasawa, S., Yin, L. (2016):New insights into the antioxidant Activity and components in crude oat oil and soybean oil.J Food Sci Technol.,53(1):808-815.

9. Chen, J., Power, K. A., Mann, J., Cheng, A., Thompson, L. U. (2007): Flaxseed alone or in Combination with tamoxifen inhibits MCF-7 breast tumor growth in overiectomizedathymic mice with high circulating levels of estrogen. ExpBiol Med (Maywood).,232:1071-1080.

10. Dave Oomah, B., Laurie Sitter. (2009): Characteristics of flaxseed hull oil. J food chem., 114: $623-628$.

11. Goyal, A., Sharma, V., Upadhyay, N., Gill, S., Sihag, M. (2014): Flax and flaxseed oil: an ancientmedicine \& modern functional food. J Food Sci Technol., 51:1633-53.

12. Hardman, W. E. (2007): Dietary canola oil suppressed growth of implanted MDA-MB 231 human breast tumors in nude mice. Nutr Cancer., 57:177-183.

13. Kinney, A.J., Cahoon, E. B., Damude, H. G., Liu, Z. B. (2004): Production of very long chain polyunsaturated fatty acids in oilseed plants. US20040172682 A1.

14. MacLennan, M., Ma, D. W. (2010): Role of dietary fatty acids in mammary gland development and breast cancer. Breast Cancer Res., 12:211.

15. Menendez, J. A., Lupu, R., Colomer, R. (2005): Exogenous supplementation with omega-3 polyunsaturated fatty acid docosahexaenoic acid (DHA; 22:6n-3) synergistically enhancestaxane cytotoxicity and downregulates Her-2/ neu (c-erbB-2) oncogene expression in human breast cancer cells. Eur J Cancer Prev., 14:263-270.

16. Menendez, J. A., Vazquez-Martin, A,.Ropero, S., Colomer, R., Lupu, R. (2006): HER2 (erbB-2)-targeted effects of the omega-3 polyunsaturated fatty acid, alpha-linolenic acid (ALA;18:3n-3), in breast cancer cells: the 'fat features' of the 'Mediterranean diet' as an 'anti-HER2 cocktail'. ClinTranslOncol., 8:812-820.

17. Rishika, C., Karishma, C., Yasmeen, K., Ennus, T. T., Sayeed, A. (2015):Characterization of Linum usitatissimum L. oil obtained from different extraction technique and in vitro antioxidant potential of supercritical fluid extract. J Pharm Bioall Sci., 7(4):284-288.

18. Stoll, B. A. (2002): N-3 fatty acids and lipid peroxidation in breast cancer inhibition. Br J Nutr., 87:193-198.

19. Swanson, D., Block, R., Mousa, S. A.(2012): Omega-3 fatty acids EPA and DHA: health benefitsthroughout life. AdvNutr., 3:1-7.

20. Welch, A. A., Shakya-Shrestha, S., Lentjes, M. A., Wareham, N. J., Khaw, K. T. (2010):Dietary intake and status of n-3 polyunsaturated fatty acids in a population of fish-eating and non-fish-eating meat-eaters, vegetarians, and vegans and the precursor product ratio of $\alpha$-linolenic acid to long-chain n- 3 polyunsaturated fatty acids: results from the EPIC-Norfolk cohort. Am J ClinNutr.,92:1040-51. 